\title{
Decompression of morbidity and the workforce
}

\author{
Countries are advancing retirement age as life expectancy advances. But increases in healthy life expectancy are \\ not keeping pace with total life expectancy, lengthening the portion of life spent with disability and threatening the \\ capacity of individuals to work longer. Now, a study forecasts healthy life expectancy for people in England in 2035.
}

\section{John W. Rowe and Lisa Berkman}

A s life expectancy advances globally and the number and proportion of older people in societies continue to rise, understanding whether this is 'healthy longevity' or whether we are only extending periods of disability before death has broad implications for many societal institutions. One area that is especially affected is retirement benefits. Many countries have increased the retirement age in an effort to keep older people in the labor force and reduce the effect of population aging on social-insurance trust funds and budgets. Such a seemingly simple 'fix' to an important problem assumes that, as longevity advances, older persons will be able to function effectively in the workforce for longer periods. With these considerations in mind, in this issue of Nature Aging, Lynch et al. present findings that such an assumption may not be valid.

Lynch et al. ${ }^{1}$ analyzed past and projected future trends in life expectancy and in healthy, disability-free life expectancy (which they term 'healthy working life expectancy' (HWLE)) in men and women in England between 50 and 75 years of age. They define 'healthy' as negative answers to telephone survey questions regarding the presence or absence of chronic conditions that impair capacity to carry out day-to-day activities.

Looking backward, they estimate that life expectancy at age 50 rose by 5.4 years in men between 1996 and 2018, while HWLE rose by only 2.0 years between 1996 and 2014 . For women, life expectancy increased by 4.1 years - again outstripping the increase in HWLE, which was 1.91 years. Looking forward, they project that by 2035 life expectancy will increase by 2.7 more years for men and HWLE will increase by only 0.2 years. For women, life expectancy will rise by an additional 1.9 years and HWLE will rise by 0.8 years. This failure of healthy life expectancy to keep pace with overall life expectancy is similar to findings of other studies in the field. For instance, the WHO (World Health Organization) reported that, globally, the increase in life expectancy

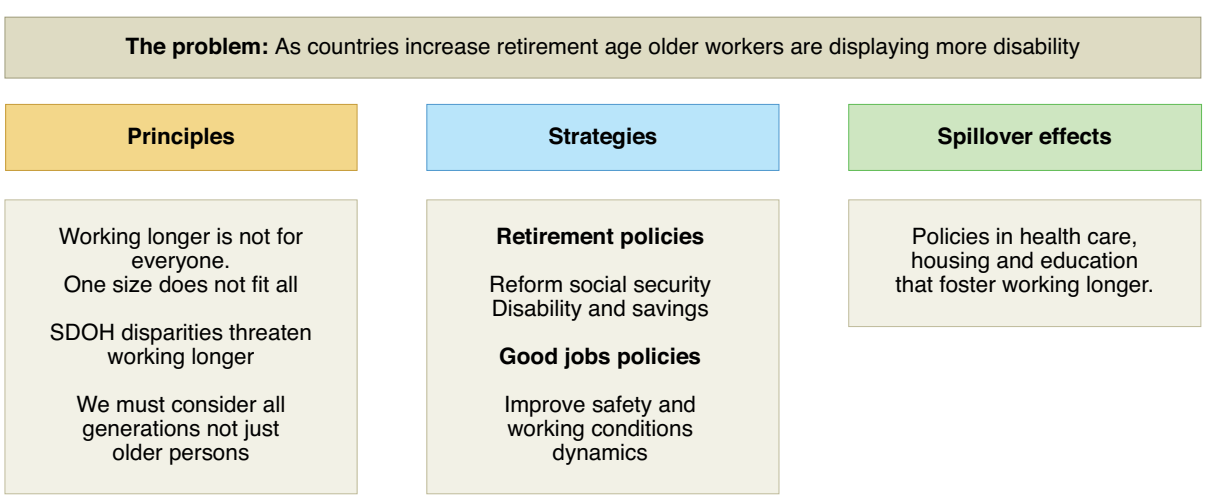

Fig. 1 | As countries increase retirement age, older workers are displaying more disability. Direct and indirect strategies that can enhance the likelihood of older workers remaining in the work force longer, and successfully retiring. SDOH, social determinants of health.

from 2000-2019 (6.6 years) outstripped the increase in healthy (disability-free) life expectancy (5.4 years), thus extending the period of life with functional impairment ${ }^{2}$. What factors are driving this trend and what can we do about it?

Work on healthy life expectancy is informed by the concept of 'compression of morbidity', which holds that if life expectancy advances slower than the age of first disability, then the portion of life characterized by functional impairment shortens. An important component of understanding healthy life expectancy is integrating heterogeneity into our models. By this, we mean the very substantial variation between individuals in their adoption of diseases, and especially of functional impairment, with advancing age. This heterogeneity is driven by many factors, including genetics, lifestyle factors and socioeconomic conditions (such as educational attainment and income). An understanding of heterogeneity and health disparities is central to identifying effective policy approaches to working longer. From an evidence-based perspective, for instance, House and colleagues ${ }^{4}$ published a landmark assessment of whether the relationship between age and health is influenced by socioeconomic status (as defined by income and educational attainment). In what may be considered a harbinger of the current focus on social determinants of health, they noted that the compression of morbidity and functional limitations into the later stages of the life course is realized to a much greater degree among those who are bettereducated, as compared with those who are less-educated, and concluded that "The vast bulk of the preventable morbidity and functional limitations in the US is concentrated in the lower socio-economic strata of our society."

Extending this work to a longitudinal analysis of a large national US database from 1986 to 2002, in 2005, House and his colleagues ${ }^{5}$ noted that education has a greater role relative to income in the onset of functional limitations, whereas income has much stronger effects on their progression or course; and that educational disparities in the onset, and hence of compression, of functional limitations were increasing over time.

Lynch et al. ${ }^{1}$ show overall patterns for men and women but discuss inequalities in health and the work environment. Follow-up studies will be needed to understand how 
such inequities may influence morbidity decompression in English society.

Concerns regarding the effect of shortened HWLE on the participation of older persons in the workforce have recently been aggravated by the observation that the share of retirees in the US population spiked from a previous level of $18 \%$ to almost $20 \%$ during the COVID-19 pandemic, driven primarily by a precipitous decline in the rate of retirees re-entering employment. Such trends are not characteristic of all recessions and the recent experience is probably related to the health effects of the pandemic (including illness), which we know disproportionately affects underprivileged populations, or hesitancy to re-enter a workplace owing to community transmission. As such, the retirement-to-employment transition rates may revert to previous levels over time ${ }^{6}$. The data analyzed by Lynch et al. ${ }^{1}$ did not allow the authors to estimate the effect of the pandemic.

Crimmins and her colleagues, including Beltran-Sanchez, have published a series of papers on trends in morbidity compression $^{7-9}$. Their findings include the observation that, while active life expectancy may have increased recently in white men due to advances in life expectancy, the number of years with a disability is advancing in all racial groups ${ }^{7}$ and - across the whole population - there is lack of evidence for overall ongoing morbidity compression in the USA, when morbidity is defined as having a disease or mobility restriction ${ }^{8}$. Crimmins concludes that although lifestyle changes, such as diet, exercise and smoking cessation, may have some marginal effect, substantial future morbidity compression will require interventions that slow the aging process itself'. The study by Lynch et al. ${ }^{1}$ provides further evidence of morbidity decompression in the future.

But there may be subsets of the population and the workforce who pose opportunities for improvement short of modifying biological aging. In an important observation regarding the relationship of socioeconomic status to trends in healthy longevity, Cantu and colleagues ${ }^{10}$ reported that between 2000 and 2010 healthy life expectancy significantly decreased for white men and women with less than 12 years of schooling, due to increases in disability prevalence. During this time, healthy life expectancy increased among collegeeducated white individuals due to decreases in age-specific mortality and disability prevalence at older ages. When we look at both socioeconomic inequalities in healthy life expectancy and at trends in population healthy aging by birth cohort, we find two important trends. First, there is some limited evidence that recent birth cohorts - of men and women who are now middle-aged - may not be as healthy as current retirees, and they may have a less-optimistic future than those now currently over 60 , at least in the USA. The situation in relation to socioeconomic inequalities in life expectancy, and perhaps healthy life expectancy, is more disturbing. Here we see large and currently widening inequalities ${ }^{11}$. Thus, identifying policies and programs to reduce disparities, delay disability, and widen active life expectancy and workforce participation may be our most promising approach to closing health inequities, as well as improving population health and opportunities for continued participation in the labor force.

Policy-makers must understand that both retirement and working-longer policies are inextricably linked to social policies, educational opportunities and resources aimed at reducing disadvantages for many lower- and middle-wage workers and their families. They are inseparable. Raising the retirement age without considering working conditions themselves, as well as the health of workers, will further leave behind alreadydisadvantaged men and women in the labor force.
As shown in Fig. 1, key considerations in the development of both good jobs and effective retirement policies include recognition of variability across individuals in their capacities and preferences, a focus on the effect of social determinants, and an intergenerational perspective that avoids pitting one generation against another and considers the needs of each generation6. The findings reported by Lynch et al. in this issue ${ }^{1}$ emphasize the riskiness of blindly advancing retirement age without a concomitant set of policies and programs to support workers and retirees.

\section{John W. Rowe (D) ${ }^{1 \times}$ and Lisa Berkman²} ${ }^{1}$ Columbia Aging Center and Department of Health Policy and Management, Mailman School of Public Health, Columbia University, New York, NY, USA. ${ }^{2}$ Center for Population and Development Studies and T. H. Chan School of Public Health, Harvard University, Cambridge, MA, USA.

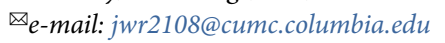

Published online: 20 January 2022

https://doi.org/10.1038/s43587-021-00163-y

References

1. Lynch, M., Bucknall, M., Jagger, C. \& Wilkie, R. Nat. Aging https://doi.org/10.1038/s43587-021-00161-0 (2022).

2. WHO. Life expectancy and Healthy life expectancy. who.int https://go.nature.com/3ydaQsd (accessed December 2020).

3. Fries, J. F. N. Engl. J. Med. 303, 130-135 (1980).

4. House, J. S., Kessler, R. C. \& Herzog, A. R. Milbank Q. 68 , 383-411 (1990).

5. House, J. S., Lantz, P. M. \& Herd, P. J. Gerontol. B Psychol. Sci. Soc. Sci. 60, 15-26 (2005).

6. Berkman, L. \& Truesdale, B. Overtime: The Future of Working Longer in America (Oxford Univ. Press, in the press).

7. Solé-Auró, A., Beltrán-Sánchez, H. \& Crimmins, E. M. Popul. Res. Policy Rev. 34, 1-18 (2015).

8. Crimmins, E. M. \& Beltran-Sanchez, H. J. Gerontol. Series B 66B, 75-86 (2011).

9. Crimmins, E. M. Gerontologist 55, 901-911 (2015).

10. Cantu, P. A., Sheehan, C. M., Sasson, I. \& Hayward, M. D. J. Gerontol. Series B 76, 319-329 (2021).

11. Chetty, R. et al. J. Am. Med. Assoc. 315, 1750-1766 (2016).

\section{Acknowledgements}

L.B. reports research support from the Sloan Foundation (Working Longer: In Jeopardy 2018-11232) and the Robert Wood Johnson Foundation (Workplace Redesign for Worker Well-Being 74575)

Competing interests

The authors declare no competing interests. 